\title{
The licensing of a laboratory for manipulating radionuclides in Brazil
}

\author{
D. M. Bonotto, B. W. Tessari, G. Girello \& V. R. Roveratti \\ Departamento de Petrologia e Metalogenia, Instituto de Geociências e \\ Ciências Exatas-UNESP, Brazil
}

\begin{abstract}
Radionuclides take a major role in guidelines of environmental agencies/national organizations of countries worldwide. In Brazil, CNEN-Comissão Nacional de Energia Nuclear is responsible for managing all subjects related to nuclear energy in the country. Thus, laboratories employing radionuclides for the development of their activities must submit a "Radioprotection Plan" to CNEN in order to get an operation license. Such plan must indicate that the laboratory is exempt of risks to the people involved and designed to fit all related environmental aspects. This was the case of LABIDRO-Hydrochemical and Isotopes Laboratory that belongs to IGCE-Geosciences and Exact Sciences Institute from UNESP - the University of the State of São Paulo "Júlio de Mesquita Filho”, located at Rio Claro city, São Paulo State, Brazil. The total monthly activity of the radionuclides utilized during the laboratorial activities held at LABIDRO corresponds to $0.01 \mu \mathrm{Ci}$. This paper describes all information provided by LABIDRO in order to get the CNEN license. The LABIDRO plan also showed the expected radioactive waste released when the experiments take place and CNEN decided that it fits the guidelines established by Brazilian legislation. Therefore, LABIDRO received its license for utilizing radionuclides, which is valid until September 2016.

Keywords: radionuclides, LABIDRO-Hydrochemical and Isotopes Laboratory, CNEN-Comissão Nacional de Energia Nuclear, licensing, radioactive installation, Brazil.
\end{abstract}




\section{Introduction}

There were some initiatives for searching thorium and uranium in Brazil before the end of the II World War, mainly due to agreements between Brazil and USA and by suggestions of Admiral Álvaro Alberto to the Brazilian government about the importance of the development of scientific activities related to the atomic energy [1]. However, it was only in 1947 that Brazil officially engaged on the formulation of a politics for the use of thorium resources in the country with the creation of the Comissão de Fiscalização dos Minerais Estratégicos, linked to the General Secretary of the National Security Council [2].

The Law 1310 published on 15 January 1951 created the CNPq-Conselho Nacional de Pesquisa and an important fact was the organization and control of the nuclear sector as it was predicted that "the State through the Conselho Nacional de Pesquisa or, when necessary, the Head State of the Armored Forces or another organism designated by the Republic President, will control all activities related to the use of the atomic energy, without prejudice of the liberty for scientific and technological research" [1]. Others competences of the CNPq were "to increment the research and prospection of the reserves existing in Brazil of the materials appropriate for the utilization of the atomic energy" as well to adopt initiatives necessary to the investigation and industrialization of the atomic energy and its applications [1]. In order to execute the nuclear energy politics, the $\mathrm{CNPq}$ created in January 1955 the Atomic Energy Commission (Martins, 1989).

However, in 1952, the commercialization of fissile Brazilian ores changed from $\mathrm{CNPq}$ to CEME-Comissão de Exportação de Materiais Estratégicos that was created for this purpose and was linked to the External Relations Ministry [3]. CEME celebrated some agreements for selling thorium oxide and monazite to the USA and the first activities of the CNPq were a) to purchase three ultra centrifuges from Occidental Germany in order to start the isotopic uranium enrichment in Brazil and b) to invite the French company Societé de Produits Chimiques des Terres Rares to project a plant for processing uranium to be settled at Poços de Caldas city, Minas Gerais State [1]. The centrifuges arrived in Brazil some years later and the factory named Poços de Caldas Atomic Plant had its construction initiated in 1959, but it was stopped in $9^{\text {th }}$ August 1961 due to a decision of the National Commission for Nuclear Energy for a re-evaluation of the mineral reserves as the amount of ore did not justify the plant construction [1].

The CNPq developed its activities related to the use of the atomic energy until a) $31^{\text {st }}$ August 1956 when the Register 39872 created the IEA-Instituto de Energia Atômica (now IPEN-Instituto de Pesquisas Energéticas e Nucleares) and b) 10 ${ }^{\text {th }}$ October 1956 when the Register 40-130 created the CNEN-Comissão Nacional de Energia Nuclear, directly linked to the Republic Presidency as an organism responsible by all aspects involved in the atomic politics [1]. Thus, CEME disappeared and occurred as well a re-orientation of the research involving fissile materials in Brazil, with emphasis in uranium [2, 3]. 
In 1960, CNEN was transferred to the Republic Presidency (Mines and Energy Ministry) and the Law 4118/62 published in 27 ${ }^{\text {th }}$ August 1962 established the National Politics for Nuclear Energy where it was defined the Union monopole on "the research and mining of nuclear ore deposits situated in the national territory; the commercialization of the nuclear ores and their concentrates; the nuclear elements and their compounds; the fissile and fertile materials; the artificial radioisotopes and radioactive substances of the three series; the nuclear products; the production of nuclear materials and their industrialization" [1]. Thus, all previous rights and obligations assumed by $\mathrm{CNPq}$ in this field were transferred to CNEN, which started to give support to others organisms integrating the National Plan for Nuclear Energy like IEAInstituto de Energia Atômica of the University of São Paulo, IPR-Instituto de Pesquisas Radioativas of the Federal University of Minas Gerais and IENInstituto de Energia Nuclear of the Federal University of Rio de Janeiro [1].

Further development occurred in the Brazilian nuclear legislation up to creation by CNEN of the CBTN-Companhia Brasileira de Tecnologia Nuclear and CDTN-Centro de Desenvolvimento de Tecnologia Nuclear in Belo Horizonte, Minas Gerais State, as a consequence of the Law 5740 published on $1^{\text {st }}$ December 1971. CDTN developed most of the processes for uranium extraction from the ores of the Poços de Caldas plateau [1]. CBTN could realize mineral research through agreement with CPRM-Companhia de Pesquisa de Recursos Minerais.

The Law 6189/74 published in $16^{\text {th }}$ December 1974 created NUCLEBRÁSEmpresas Nucleares Brasileiras Sociedade Anônima that succeeded CBTN and according to it "the Union will exert the monopole through CNEN as a superior organism of orientation, planning, supervising, fiscalization and scientific research and through NUCLEBRÁS and subsidiaries as an execution organism" [1]. According to Article 16 of this Law "when it is assured the existence of stocks for the execution of the National Program for Nuclear Energy as well of the reserves related to Article 14, then, NUCLEBRÁS, after authorization of the Republic President and National Security Council, can export the excess in the highest possible grade of treatment” [1].

The Brazilian Nuclear Program suffered a deep reformulation in 1988 after the publication of the Register 2464 in $31^{\text {st }}$ August 1988 that caused the extinction of NUCLEBRÁS and its substitution by INB-Indústrias Nucleares do Brasil controlled by CNEN. The Register 96622 published in $33^{\text {rd }}$ August 1989 authorized INB to create UB-Urânio do Brasil, a subsidiary of INB and a mixed corporation responsible by the prospection and mining of the nuclear ore, production, processing and commercialization of uranium concentrates [1]. The CDTN and Poços de Caldas laboratory were also transferred to CNEN and occurred in 1994 a new reorganization of uranium production area, causing the extinction of the UB-Urânio do Brasil, whose activities were directed to the Directory of the Mineral Resources from INB [4].

LABIDRO-Hydrochemical and Isotopes Laboratory that belongs to IGCEGeosciences and Exacts Sciences Institute from UNESP-University of the State of São Paulo “Júlio de Mesquita Filho”, located at Rio Claro city, São Paulo 
State, Brazil, has started its operation in 1988. Because LABIDRO has utilized radionuclides for the development of research activities, it has been necessary submit to CNEN along the years all requested information for getting the operation license. This paper describes the "Radioprotection Plan" provided by LABIDRO in order to get the last CNEN license.

\section{Classification of the radioactive installation}

Since its beginning, LABIDRO has been involved on the use of small amounts of radionuclides in research. The first researcher licensing provided by CNEN occurred on $5^{\text {th }}$ November 1985 (Research License AP-0193, Protocol CNEN No. 27400.000619/85).

Table 1 describes the radionuclides utilized at LABIDRO, which were freely obtained from Research Institutes, purchased from IPEN (Instituto de Pesquisas Energéticas e Nucleares) - CNEN/São Paulo State or imported according to criteria established by Departamento de Instalações e Materiais Nucleares from CNEN/Rio de Janeiro State. The installation may be inserted in Group IV according to item 4 from CNEN Rule NE-6.02 established in July 1998. This is because the Normalized Activity corresponds to $0.01 \mu \mathrm{Ci}$ (Table 1 ) which is well below the guideline value of $1 \mu \mathrm{Ci}$ for this group.

Table 1: $\quad$ Radionuclides utilized at LABIDRO.

\begin{tabular}{|c|c|c|c|c|c|}
\hline Radionuclide & $\begin{array}{l}\text { Half } \\
\text { life }\end{array}$ & Class & State & $\begin{array}{c}\text { Work } \\
\text { condition* }\end{array}$ & Monthly activity \\
\hline U-232 & $72 \mathrm{a}$ & A & Liquid & I & $0.030 \mu \mathrm{Ci}$ \\
\hline U-232 & 72 a & A & Liquid & II & $0.000030 \mu \mathrm{Ci}$ \\
\hline Po-209 & $102 \mathrm{a}$ & A & Liquid & $\mathrm{I}$ & $0.46 \mu \mathrm{Ci}$ \\
\hline Po-209 & 102 a & A & Liquid & II & $0.000035 \mu \mathrm{Ci}$ \\
\hline Ва-133 & 10,7 a & A & Liquid & I & $0.45 \mu \mathrm{Ci}$ \\
\hline Ва-133 & $10,7 \mathrm{a}$ & A & Liquid & II & $0.00066 \mu \mathrm{Ci}$ \\
\hline Ra-226 & 1600 a & A & Liquid & I & $0.0084 \mu \mathrm{Ci}$ \\
\hline Th-229 & 7340 a & A & Liquid & I & $0.000019 \mu \mathrm{Ci}$ \\
\hline Cs-137 & 30 a & C & $\begin{array}{l}\text { Sealed } \\
\text { source }\end{array}$ & I & $0.040 \mu \mathrm{Ci}$ \\
\hline Co-60 & $5,3 \mathrm{a}$ & B & $\begin{array}{l}\text { Sealed } \\
\text { source }\end{array}$ & I & $0.0040 \mu \mathrm{Ci}$ \\
\hline U-nat & $\begin{array}{c}4,5 \mathrm{Ga} \\
(\mathrm{U}-238)\end{array}$ & $\mathrm{D}$ & $\begin{array}{l}\text { Sealed } \\
\text { source }\end{array}$ & I & $0.19 \mu \mathrm{Ci}$ \\
\hline Th-nat & $\begin{array}{c}14 \mathrm{Ga} \\
(\mathrm{Th}-232)\end{array}$ & B & $\begin{array}{l}\text { Sealed } \\
\text { source }\end{array}$ & I & $0.056 \mu \mathrm{Ci}$ \\
\hline $\mathrm{An}^{* *}$ & & & & & $0.01 \mu \mathrm{Ci}$ \\
\hline
\end{tabular}

*I- Simple storage; II- Very simple wet operation - aliquot.

**Normalized activity calculated according to item 4.2.1 of CNEN Rule NE-6.02 established in July 1998. 


\section{Laboratory detailing}

LABIDRO comprises a whole area of about $70 \mathrm{~m}^{2}$ distributed in 5 rooms aimed to the chemical, physical and physical-chemical characterization of waters, as well to the evaluation of some radionuclides in samples of waters, rocks, minerals, sediments and soils. Four rooms are located in the basement of the building where is situated DPM-Departamento de Petrologia e Metalogenia, whereas one is located in the upper level of the building. LABIDRO possesses the analytical infra-structure needed to perform a large number of essays, containing different sectors positioned in distinct rooms, numbered from 1 to 5 .

Room 1 (basement) receives the samples and allows the water filtering.

Room 2 (basement) possesses two 1 ton lead shielding in which is inserted a $3 \times 3$ ” $\mathrm{NaI}(\mathrm{Tl})$ scintillation detector for performing gamma spectrometric readings of radioactive calibration sources and samples of waters, rocks, minerals, sediments and soils. In addition, there is also two smaller ( 100 kg) lead shielding for the storage of sealed radioactive sources (Cs-137, Co-60, U-nat, Th-nat) and radionuclides in the liquid state (Po-209, Ba-133, Ra-226, Th-229) for the preparation of diluted solutions whose aliquots are utilized in the samples analysis. Table 1 describes the physical state and monthly activity of the radionuclides stored in the lead shielding. In the case of U-232, the storage and manipulation occur at Room 3, instead of Room 2.

Room 3 (basement) has been utilized to evaporation/drying of the solutions, ionic exchange reactions and manipulation of the radionuclides U-232, Po-209 and Ba-133 that are added to the samples as aliquots obtained from the selected dilutions. The purpose is to act as tracer for providing reliable evaluation of the chemical yield related to the analysis of each sample. The flasks containing these solutions are properly identified and the storage has been performed in plastic trays of easy decontamination from occasional/accidental spills. They are stored in a cabinet signaled with the universal radioactivity symbol. The manipulation of the radionuclides has been realized in a well-signaled exhaustion coif for this specific use that has been installed in a stand covered with plastic and absorbing paper sheet.

Room 4 (basement) has been utilized for emanometric (oxygen, carbon dioxide, sulphide gas), spectrophotometric and potentiometric $(\mathrm{pH}$, redox potential, electrodeposition) essays in water samples; therefore, the radionuclides presence is only verified when the electrodeposition takes place.

Room 5 (upper level) contains the alpha spectrometry system and the data acquisition system of the two gamma spectrometers. Radionuclides are not manipulated in it, unlike at Room 3. The unique exception are the radioactive sources (stainless steel and copper/resin disks) containing the U-232 and Po-209 aliquots added to the samples and recovered after electrodeposition, which are inserted in the vacuum chambers for the alpha spectrometric readings. These sources exhibit low activity, i.e. a maximum of $0.1 \mathrm{~Bq}$ each, depending on the chemical yield of the extraction procedure. They often require a counting time of 3-4 days for reaching the necessary statistics in a peak. 
Thus, the radionuclide manipulation (non-sealed sources) is restricted to Room 3, whereas their storage occurs at Rooms 2 and 3. Room 3 possesses a stainless steel sink and lateral stand, tap elbow-opened and a dump containing pedal and the radiation international symbol. The Room 2 and Room 3 doors are signaled with the universal radioactivity symbol, as well as with the area classification. The Room 3 floor is covered by smooth material, whereas its walls are painted by washable ink. The walls-floor junction is rounded.

\section{Laboratory operation and use}

LABIDRO is managed by a chief investigator and a technician (chemist) who supervises the development of essays realized by $\mathrm{Ms}$ and $\mathrm{PhD}$ students for the development of their dissertations and theses.

All people engaged with the LABIDRO activities are trained on the use of the several analytical techniques developed at Rooms 1-5. Each user receives the manual "Basic Rules for Working and Security at LABIDRO" that contains all necessary instructions for the safe radionuclide manipulation. The manual also describes the major initiatives to prevent the contamination of humans and work area, as well the procedures during eventual emergency situations. LABIDRO possesses four dosimeters for evaluating occasional contamination due to accidental events like solution spills.

The radionuclide manipulation is realized in such a way that the exposition rate is low. This is confirmed by data reported in Table 2 that shows the annual dose estimated in a hypothetical scenario in which an adult member of the public would stay over a soil surface containing all radioactive sources represented in Table 1 . The total dose exposition corresponds to $0.01 \mathrm{mSv} / \mathrm{year}$ and is well below the guideline value of $1 \mathrm{mSv} /$ year for members of the public (Rule CNEN-NN-3.01 published in January 2005). It is important emphasize that the

Table 2: $\quad$ Dose due to radionuclides utilized at LABIDRO.

\begin{tabular}{ccccc}
\hline Radionuclide & Class & $\begin{array}{c}\text { Activity } \\
\left(\mathrm{Bq} / \mathrm{m}^{2}\right)\end{array}$ & $\begin{array}{c}\text { Dose Conversion Factor } \\
\left(\times 10^{-15} \mathrm{~Sv} / \mathrm{h} \text { per } \mathrm{Bq} / \mathrm{m}^{2}\right)^{*}\end{array}$ & $\begin{array}{c}\text { Annual } \\
\text { Dose } \\
\left(\times 10^{-8} \mathrm{~Sv}\right)\end{array}$ \\
\hline U-232 & A & 1100 & 2.91 & 2.8 \\
Po-209 & A & 0.13 & $0.029($ for Po-210) & $3.3 \times 10^{-6}$ \\
Ba-133 & A & 24.4 & 1340 & 28.6 \\
Ra-226 & A & 296 & 22 & 5.7 \\
Th-229 & A & 0.69 & 284 & 0.17 \\
Cs-137 & C & 1480 & 10.8 & 14.0 \\
Co-60 & B & 148 & 8280 & 1070.0 \\
U-nat & D & 7030 & 1.52 (for U-238) & 9.4 \\
Th-nat & B & 2220 & 1.64 (for Th-232) & 3.2 \\
\hline Total & \multicolumn{4}{c}{1134} \\
*NEN Rule 3.01/011:2011 - Dose coefficient for members of the public \\
exposition.
\end{tabular}


values in Table 1 are over estimated as it has been assumed an exposition time of 8760 years ( 1 year) to the stored sources, whereas the real value does not reach 2 hours/year.

\section{Waste management}

There is no record of accidental spills at LABIDRO as a consequence of the development of laboratorial activities involving the radionuclide manipulation (addition of U-232, Po-209 and Ba-133 aliquots to water and sediments samples). Therefore, it has not been identified any contamination of apron, gloves or paper sheet/plastic over the bench. However, LABIDRO possesses an appropriate container for the storage of waste in the case of an occasional emergency situation. It is located in a place of restrict access, whose door is identified with the universal symbol of radioactive material.

The pipette tips have been normally re-utilized and sometimes discarded in the collection system of the urban litter. Under such circumstance, they have not exceeded the maximum specific activity of $2 \mu \mathrm{Ci} / \mathrm{kg}\left(=2 \times 10^{-3} \mu \mathrm{Ci} / \mathrm{g}\right)$ established by Rule CNEN-NE-6.05 published in December/1985 (Management of Radioactive Waste in Nuclear Installations). This is illustrated in Table 3 that shows the specific activity considering the hypothetical situation of complete absorption in the tip of the whole amount of the radionuclide utilized. The conservative hypothesis is that $2 \%$ of the radionuclide activity remains absorbed in the tip and the adoption of this value would imply on much lower specific activity data.

Table 3: $\quad$ Specific activity of radionuclide utilized at LABIDRO assuming complete absorption in the tip of the whole amount of the radionuclide utilized.

\begin{tabular}{cccc}
\hline Radionuclide & $\begin{array}{c}\text { Aliquot added } \\
\text { to the sample }\end{array}$ & $\begin{array}{c}\text { Tip } \\
\text { weight }\end{array}$ & Specific activity \\
\hline $\mathrm{U}-232$ & $0.30 \times 10^{-5} \mu \mathrm{Ci}$ & $0.75 \mathrm{~g}$ & $4.0 \times 10^{-6} \mu \mathrm{Ci} / \mathrm{g}$ \\
Po-209 & $0.35 \times 10^{-5} \mu \mathrm{Ci}$ & $0.75 \mathrm{~g}$ & $4.7 \times 10^{-6} \mu \mathrm{Ci} / \mathrm{g}$ \\
Ba-133 & $0.66 \times 10^{-3} \mu \mathrm{Ci}$ & $0.75 \mathrm{~g}$ & $0.9 \times 10^{-3} \mu \mathrm{Ci} / \mathrm{g}$ \\
\hline
\end{tabular}

The stainless steel and copper/resin disks utilized for U-232 and Po-209 deposition during their aliquot use when chemically processing the samples constitute another solid waste generated by LABIDRO from the radionuclide manipulation. Ba-133 has been differently utilized, remaining in solution. Table 4 shows the specific activity in each disk, under the hypothesis that occur deposition of the whole amount of the radionuclide utilized. The estimated values are much lower than the maximum specific activity of $2 \times 10^{-3} \mu \mathrm{Ci} / \mathrm{g}$ for disposal in the collection system of the urban litter.

The stainless steel and copper/resin disks containing U-232 and Po-209 possess alpha emitters whose activity concentration is lower than $10^{-2} \mathrm{Ci} / \mathrm{m}^{3}$. They are classified as low level solid waste (SBN) according to Rule CNEN-NE- 
6.05 published in December 1985 as exhibit surface exposition rate much lower than $0.2 \mathrm{R} / \mathrm{h}$ (Table 5), even under the assumption that occur deposition of the whole amount of the radionuclide utilized.

Table 4: $\quad$ Specific activity of radionuclide utilized at LABIDRO assuming complete deposition in the disk of the whole amount of the radionuclide utilized.

\begin{tabular}{cccc}
\hline Radionuclide & $\begin{array}{c}\text { Aliquot added } \\
\text { to the sample }\end{array}$ & $\begin{array}{c}\text { Disk } \\
\text { weight }\end{array}$ & Specific activity \\
\hline $\mathrm{U}-232$ & $0.30 \times 10^{-5} \mu \mathrm{Ci}$ & $1.9 \mathrm{~g}$ & $1.5 \times 10^{-6} \mu \mathrm{Ci} / \mathrm{g}$ \\
Po-209 & $0.35 \times 10^{-5} \mu \mathrm{Ci}$ & $1.3 \mathrm{~g}$ & $2.7 \times 10^{-6} \mu \mathrm{Ci} / \mathrm{g}$ \\
\hline
\end{tabular}

Table 5: $\quad$ Surface exposition rate of the radionuclide utilized at LABIDRO assuming complete deposition in the disk of the whole amount of the radionuclide utilized.

\begin{tabular}{ccccc}
\hline Radionuclide & $\begin{array}{c}\text { Aliquot added } \\
\text { to the sample }\end{array}$ & $\begin{array}{c}\text { Disk } \\
\text { area }\end{array}$ & $\begin{array}{c}\text { Activity } \\
\left(\mathrm{Bq} / \mathrm{m}^{2}\right)\end{array}$ & $\begin{array}{c}\text { Surface exposition } \\
\text { rate }\left(\times 10^{-13} \mathrm{R} / \mathrm{h}\right)\end{array}$ \\
\hline $\mathrm{U}-232$ & $0.30 \times 10^{-5} \mu \mathrm{Ci}$ & $4.5 \mathrm{~cm}^{2}$ & 244.4 & 711.2 \\
Po-209 & $0.35 \times 10^{-5} \mu \mathrm{Ci}$ & $4.5 \mathrm{~cm}^{2}$ & 288.9 & 8.4 \\
\hline Total & & & & 719.6 \\
\hline
\end{tabular}

The U-232, Po-209 and Ba-133 aliquots added to the samples are in the liquid state. Table 6 shows an estimate of the monthly activity under the hypothetical situation that the whole amount would be eliminated in the sewer network. The values are much lower than the maximum specified by Rule CNEN-NE-6.05 published in December 1985 (Table 6). Therefore, they can be eliminated as liquid waste.

Table 6: Monthly activity of the radionuclides utilized at LABIDRO assuming complete elimination in the sewer network (average monthly volume $=146 \mathrm{~m}^{3}$ ).

\begin{tabular}{|c|c|c|c|c|}
\hline Radionuclide & $\begin{array}{l}\text { Monthly } \\
\text { activity }\end{array}$ & $\begin{array}{r}\text { Activity } \\
\text { average } \mathrm{n} \\
\mathrm{V}\end{array}$ & $\begin{array}{l}\text { ed by the } \\
\text { hly sewer } \\
\text { le }\end{array}$ & $\begin{array}{l}\text { Table } 6- \\
\text { Column } 1^{*}\end{array}$ \\
\hline U-232 & $3.0 \times 10^{-5} \mu \mathrm{Ci}$ & $\begin{array}{c}2.0 \times 10^{-7} \\
\mu \mathrm{Ci} / \mathrm{m}^{3}\end{array}$ & $\begin{array}{c}7.4 \times 10^{-3} \\
\mathrm{~Bq} / \mathrm{m}^{3}\end{array}$ & $3 \times 10^{7} \mathrm{~Bq} / \mathrm{m}^{3}$ \\
\hline Po-209 & $3.5 \times 10^{-5} \mu \mathrm{Ci}$ & $\begin{array}{l}2.4 \times 10^{-7} \\
\mu \mathrm{Ci} / \mathrm{m}^{3}\end{array}$ & $\begin{array}{c}9.2 \times 10^{-3} \\
\mathrm{~Bq} / \mathrm{m}^{3}\end{array}$ & $\begin{array}{c}7.4 \times 10^{5} \mathrm{~Bq} / \mathrm{m}^{3} \\
(\text { for Po-210) }\end{array}$ \\
\hline Ва-133 & $0.66 \times 10^{-3} \mu \mathrm{Ci}$ & $\begin{array}{l}4.5 \times 10^{-6} \\
\mu \mathrm{Ci} / \mathrm{m}^{3}\end{array}$ & $\begin{array}{c}170 \times 10^{-3} \\
\mathrm{~Bq} / \mathrm{m}^{3}\end{array}$ & $\begin{array}{c}1.8 \times 10^{8} \mathrm{~Bq} / \mathrm{m}^{3} \\
(\text { for Ba-131) }\end{array}$ \\
\hline
\end{tabular}

*Rule CNEN-NE-6.05 published in December 1985 (Management of Radioactive Waste in Nuclear Installations).

The Rule CNEN-NE-6.05 published in December 1985 also establishes that the total annual amount of radionuclides (except $\mathrm{H}-3$ and $\mathrm{C}-14$ ) released into the 
sewer network should not exceed $1 \mathrm{Ci}$. Table 7 shows the activity estimate considering that the whole amount of U-232, Po-209 and $\mathrm{Ba}-133$ would be eliminated in the sewer network. The annual activity corresponds to $868 \times 10^{-5} \mu \mathrm{Ci}$ that is well below the guideline value of $1 \mathrm{Ci}$, again assuring the possibility of their release as liquid waste.

Table 7: Annual activity of the radionuclides utilized at LABIDRO assuming complete elimination in the sewer network.

\begin{tabular}{cc}
\hline Radionuclide & Annual activity \\
\hline U-232 & $36 \times 10^{-5} \mu \mathrm{Ci}$ \\
Po-209 & $42 \times 10^{-5} \mu \mathrm{Ci}$ \\
Ba-133 & $790 \times 10^{-5} \mu \mathrm{Ci}$ \\
\hline Total & $868 \times 10^{-5} \mu \mathrm{Ci}$ \\
\hline
\end{tabular}

The U-232, Po-209 and Ba-133 aliquots added to the samples possess alpha emitters whose activity concentration is lower than $10^{-2} \mathrm{Ci} / \mathrm{m}^{3}$. They may be classified as liquid waste of low radiation level (LBN), even under the hypothetical situation that the whole amount would be eliminated in the sewer network. This is because the total activity concentration corresponds to $1.3 \mathrm{mCi} / \mathrm{m}^{3}$ (Table 8 ) which is much lower than the guideline value of $1 \mathrm{Ci} / \mathrm{m}^{3}$ established by Rule CNEN-NE-6.05 published in December 1985.

Table 8: Activity concentration of the radionuclides utilized at LABIDRO assuming complete elimination in the sewer network.

\begin{tabular}{cccc}
\hline Radionuclide & $\begin{array}{c}\text { Aliquot added } \\
\text { to the sample }\end{array}$ & $\begin{array}{c}\text { Volume } \\
\text { added to } \\
\text { the sample }\end{array}$ & $\begin{array}{c}\text { Activity } \\
\text { concentration } \\
\left(\mu \mathrm{Ci} / \mathrm{m}^{3}\right)\end{array}$ \\
\hline $\mathrm{U}-232$ & $0.30 \times 10^{-5} \mu \mathrm{Ci}$ & $0.2 \mathrm{~cm}^{3}$ & 15 \\
Po-209 & $0.35 \times 10^{-5} \mu \mathrm{Ci}$ & $0.2 \mathrm{~cm}^{3}$ & 18 \\
Ba-133 & $0.66 \times 10^{-3} \mu \mathrm{Ci}$ & $0.5 \mathrm{~cm}^{3}$ & 1320 \\
\hline Total & & & 1353 \\
\hline
\end{tabular}

\section{Conclusion}

This paper described the information provided by LABIDRO in order to get the CNEN license for the use of radionuclides in research. The following radionuclides have been utilized by LABIDRO: U-232 (half-life $=72 \mathrm{y}$; liquid state; monthly activity $=0.030 \mu \mathrm{Ci} /$ storage, $0.000030 \mu \mathrm{Ci} /$ manipulation), Po-209 (half-life $=102 \mathrm{y}$; liquid state; monthly activity $=0.46 \mu \mathrm{Ci} /$ storage, $0.000035 \mu \mathrm{Ci} /$ manipulation), Ba-133 (half-life $=10.7 \mathrm{y}$; liquid state; monthly activity $=0.45 \mu \mathrm{Ci} /$ storage, $0.00066 \mu \mathrm{Ci} /$ manipulation), Ra-226 (halflife $=1600 \mathrm{y}$; liquid state; monthly activity $=0.0084 \mu \mathrm{Ci} /$ storage), Th-229 (half-life $=7340 \mathrm{y}$; liquid state; monthly activity $=0.000019 \mu \mathrm{Ci} /$ storage), Cs-137 (half-life $=30 \mathrm{y}$; sealed source; monthly activity $=0.040 \mu \mathrm{Ci} /$ storage), 
Co-60 (half-life $=5.3 \mathrm{y}$; sealed source; monthly activity $=0.0040 \mu \mathrm{Ci} /$ storage), U-238 natural (half-life $=4.5 \mathrm{~Gy}$; sealed source; monthly activity = $0.19 \mu \mathrm{Ci} /$ storage), Th-232 natural (half-life = $14 \mathrm{~Gy}$; sealed source; monthly activity $=0.056 \mu \mathrm{Ci} /$ storage). The total monthly activity of these radionuclides corresponds to $0.01 \mu \mathrm{Ci}$. The "Radioprotection Plan" submitted to CNEN showed the expected radioactive waste released during the development of the laboratorial activities. After detailed analysis, CNEN decided that it fits the guidelines established by the Brazilian legislation and, therefore, LABIDRO has gotten its license for working with radionuclides, which is valid until September 2016.

\section{References}

[1] Barros, D.F. de, A indústria de urânio: um estudo comparativo da evolução da legislação internacional e brasileira, UNESP, Rio Claro, 204 pp., 2008.

[2] Martins, L.A.M., Estado e exploração mineral no Brasil - Um levantamento básico, USP, São Paulo, 349 pp., 1989.

[3] Cabral, M., A questão nuclear. Rep. Comissão Parlamentar de Inquérito do Senado Federal sobre o Acordo Nuclear do Brasil com a República Federal da Alemanha. Senado Federal, Brasília, v. 3, pp. 7-60, 1983.

[4] Cipriani, M., Mitigação dos impactos sociais e ambientais decorrentes do fechamento definitivo de minas de urânio, UNICAMP, Campinas, 332 pp., 2002. 